\title{
Ethanol Extract of Polygonatumofficinale Rhizome Inhibits Odorant-Induced Camp and Calcium Levels in Non-Chemosensory 3T3-L1 Cells
}

\author{
Yeo Cho Yoon, Sung-Hee Kim, Jin-Taek Hwang, Mi Jeong Sung, Myung-Sunny Kim, Haeng Jeon Hur, \\ Mee Ra Rhyu, Jae-Ho Park* \\ Korea Food Research Institute, 1201-62 Anyangpangyo-ro, Bundang-gu, Seongnam-si, Gyeonggi-do, Republic of Korea \\ *Corresponding author: jaehoparkmail@gmail.com
}

Received August 12, 2014; Revised October 05, 2014; Accepted October 20, 2014

\begin{abstract}
Polygonatum Officinalerhizome, a member of the liliaceae family, is commonly consumed as tea in Asia. It is also clinically used to treat obesity and fatigue in Korean traditional medicine. Although the anti-diabetic effect of POR has been described, little is known about its physiological role in the olfactory system. In this study, we investigated the effects of POR in 3T3-L1 cells expressing an odorant receptor. We have shown that the levels of cAMP and $\mathrm{Ca}^{2+}$ and the phosphorylation of Rap1A and CREB increased in response to an odorant, eugenol. POR significantly decreased the eugenol-induced increase in cAMP and $\mathrm{Ca}^{2+}$. Taken together, these data suggest that POR inhibits an odorant-induced signal transduction pathway.
\end{abstract}

Keywords: cAMP, adenylyl cyclase, olfactory, polygonatumofficinale, 3T3-L1

Cite This Article: Yeo Cho Yoon, Sung-Hee Kim, Jin-Taek Hwang, Mi Jeong Sung, Myung-Sunny Kim, Haeng Jeon Hur, Mee Ra Rhyu, and Jae-Ho Park, "Ethanol Extract of Polygonatumofficinale Rhizome Inhibits Odorant-Induced Camp and Calcium Levels in Non-Chemosensory 3T3-L1 Cells.” Journal of Food and Nutrition Research, vol. 2, no. 11 (2014): 776-780. doi: 10.12691/jfnr-2-11-3.

\section{Introduction}

Polygonatum Officinale rhizome(POR) is a perennial plant that belongs to the liliaceae family and it grows in Korea, Japan, and China. The leaves and roots of POR can be used for medicinal purposes, and the trunk can be eaten as food. Numerous reports support its clinical applications, demonstrating that POR prevents high-fat-diet-induced metabolic disorders [1], reduces adipogenesis [2], suppresses inflammation [3], and lowers hyperglycemia in diabetic mice [4]. Although POR contains many flavonoids and polyphenols that are known as phytochemicals and play various physiological roles, little is known about the components responsible forits effects. It is likely that several compounds in POR work together and to elicitvarious physiological functions.

Olfactory receptors (OR) are mainly located on the olfactory sensory neurons (OSN), which are responsible for the first step of olfactory perception. However, recent reports indicate that ORs are also expressed in nonchemosensory tissues, such as muscle, testis, heart, and spleen, and they play different physiological roles depending on the context [5]. Although heterologous systems have mainly been used to characterize ORs and their ligands and investigate the olfactory signal transduction (OST) pathway, ectopic expression of ORs also represents a model system to study different physiological roles in non-chemosensory tissues.
Interestingly, in both chemosensory and nonchemosensory tissues, odorant-induced signal transduction pathway share the same process, where cAMP and $\mathrm{Ca}^{2+}$ are crucial molecules $[5,6,7,8]$ and CREB and Rap1A serve to relay signals $[5,9,10,11]$. Odorant-induced signal transduction is initiated by the binding of odorants to their olfactory receptors [12]. The stimulated receptors activate a type III adenylyl cyclase and subsequently increase cAMP levels [13,14]. The increased intracellular cAMP increases $\mathrm{Ca}^{2+}[15]$ and stimulates phosphorylation of CREB, one of downstream targets of cAMP [9]. In addition, cAMP activates Rap1A by stimulating Epac [16] However, the role of Rap1A in OST has not been demonstrated.

In this study, we investigated the effect of POR on the odorant-induced signal transduction pathway. In addition, we evaluated the effect of POR on $\mathrm{Ca}^{2+}$, cAMP, and the downstream signal transduction pathway following stimulation by an odorant, eugenol, in non-chemosensory 3T3-L1 cells.

Pretreatment with POR decreased the eugenol-induced increase in cAMP and $\mathrm{Ca}^{2+}$ in 3T3-L1 cells. In addition, POR inhibited the phosphorylation of Rap1a and CREB, which play important roles in the OST pathway. Understanding the odorant-induced signaling pathway and its regulation in non-chemosensory cells provides a new model for investigating the different physiological roles of ORs, and it also provides a foundation for the development of drugs to modulate these signal cascades for therapeutic purposes. 


\section{Materials and Methods}

\subsection{Plant Material}

POR was obtained from the Korea plant extract bank at the Korea Research Institute of Bioscience and Biotechnology (KRIBB, Daejeon, Republic of Korea). The rhizome was dried at room temperature for 5 days and grinded. The powder was dissolved in $95 \%$ ethanol (v/v) at $50^{\circ} \mathrm{C}$ for $3 \mathrm{~h}$ and then filtered with $3 \mathrm{M}$ paper. The extracts were lyophilized and resuspended in DMSO.

\subsection{Reagents and Antibodies}

Eugenol was purchased from Sigma (St. Louis, MO, USA) and dissolved in DMSO. The $\mathrm{Ca}^{2+}$ assay kit was obtained from Molecular Devices (Sunnyvale, CA, USA), and the cAMP assay kit was purchased from Enzo Life Sciences (Plymouth Meeting, PA, USA). Antibodies against phospho-Rap1a and phospho-CREB were purchased from Cell Signaling Technology (Beverly, MA, USA) and lamin B was obtained from Abcam (Cambridge, MA, USA).

\subsection{Cell Culture}

3T3-L1 and HEK293 cells were obtained from American Type Culture Collection (Manassas, VA, USA) and cultured in Dulbecco's modified Eagle medium (DMEM) containing 10\% fetal bovine serum (FBS) and $1 \times$ antibiotic-antimycotic solution (WelGENE Inc., Daegu, Republic of Korea). All cells were cultured at $37^{\circ} \mathrm{C}$ in the presence of $5 \% \mathrm{CO}_{2}$.

\section{4. $\mathrm{Ca}^{2+}$ assay}

Cells were seeded in black 96-well plates and pretreated with POR $(0-800 \mu \mathrm{g} / \mathrm{mL})$ in a $\mathrm{CO}_{2}$ incubator for $30 \mathrm{~min}$. Then, $100 \mu \mathrm{L}$ of component Abuffer (Molecular Devices, Sunnyvale, CA, USA) was added to each well. After covering plate with foil, the cells were incubated for 30 $\min$ at room temperature, followed by $15 \mathrm{~min}$ at $37^{\circ} \mathrm{C}$. Eugenol (0-2 mM) and ionomycin ( $2 \mu \mathrm{M}$, positive control) were added using Flexstation 3 (Molecular Devices). The chemicals were added to the same volume of component A buffer into each well, and the $\mathrm{Ca}^{2+}$ level was measured according to the manufacturer's instructions.

\section{5. cAMP Assay}

3T3-L1 cells were washed with DPBS (Welgene), and serum-free HBSS (High glucose)media was added for 16$18 \mathrm{~h}$ to starve cells. After pretreatment with POR (0-800 $\mu \mathrm{g} / \mathrm{mL}$ ) for $30 \mathrm{~min}$, the starved cells were treated with eugenol (2 mM) for $7 \mathrm{~min}$ andlysed with $0.1 \mathrm{M} \mathrm{HCl}$. cAMP levels were confirmed using the Direct cAMP EIA Kit (EnzoLife Sciences), as previously described [17].

\subsection{Western Blot Analysis}

Western blotting was used to investigate protein expression in 3T3-L1 cells. Cells were plated in 6-well plates and incubated with serum-free DMEM for 16-18 h. The starved cells were pretreated with POR for $30 \mathrm{~min}$ and eugenol was added for $7 \mathrm{~min}$, as described for the
cAMP assay. The cells were then washed with PBS at $37^{\circ} \mathrm{C}$ and lysed with RIPA buffer (Bioseang, Seongnam-si, Republic of Korea) containing a protease inhibitor cocktail (Roche, Basel, Switzerland) and a phosphatase inhibitor cocktail (Roche).Cells were collected using cell scrapers and transferred to a $1.5-\mathrm{mL}$ tube. Then, the lysates were centrifuged at $12,000 \mathrm{rpm}$ for $30 \mathrm{~min}$ at $4{ }^{\circ} \mathrm{C}$. The SMART BCA Protein Assay Kit (iNtRON Biotechnology, Seongnam-si, Republic of Korea) was used to measure protein concentration. In total, $45 \mu \mathrm{g}$ of the protein was electrophoresed by SDS-PAGE, transferred to a nitrocellulose membrane, and blocked with $5 \%$ non-fat dry milk in $1 \times$ Tris buffered saline containing $0.05 \%$ Tween-20 (TBST) at room temperature for $1 \mathrm{~h}$. Then, the membranes were incubated with the appropriate primary antibody on a rocker at $4^{\circ} \mathrm{C}$ overnight. After washing with TBST, the membranes were probed with horseradish peroxidase-conjugated secondary antibody at room temperature for $1.5 \mathrm{~h}$. For visualization, the membranes were incubated with Enhanced Chemiluminescence reagents (Amersham, Piscataway, NJ, USA).

\subsubsection{Statistical analysis}

All experiments were repeated more than 3 times, and the data are expressed as the mean \pm standard deviation (SD). Group means were compared with non-parametric Kruskal-Wallis and Mann-Whitney analysis using SPSS (SPSS Inc., Armonk, NY).

\section{Results and Discussion}

\subsection{Eugenol Increased $\mathrm{Ca}^{2+}$, cAMP, and CREB Phosphorylation in 3T3-L1 Cells}

Numerous reports demonstrated that olfactory receptors (OR) are ectopically expressed in various tissues and play different physiological roles [5]. Recently, several ORs were shown to be expressed in murine adipose tissues [18]. Consistent with this, the expression of murine eugenol receptor (mol fr 73) was observed in 3T3-L1 cells differentiating into an adipocyte-like phenotype, but not in HEK293 cells (Figure 1). Although OR exert different roles in non-chemosensory tissues, cAMP and $\mathrm{Ca}^{2+}$ are crucial molecules in the odorant-induced signal cascade and olfactory signal transduction (OST) pathway $[6,7,8]$. To investigate whether cAMP and $\mathrm{Ca}^{2+}$ are increased by odorants in 3T3-L1 cells, we measured $\mathrm{Ca}^{2+}$ and cAMP levels after stimulation with an odorant, eugenol. As shown in Figure 2A, after treatment with different concentrations of eugenol, $\mathrm{Ca}^{2+}$ levels significantly increased by 5 -fold at $1 \mathrm{mM}$ and 10 -fold at $2 \mathrm{mM}$. However, little change was observed in response to treatment with 0 and $500 \mu \mathrm{M}$ eugenol.

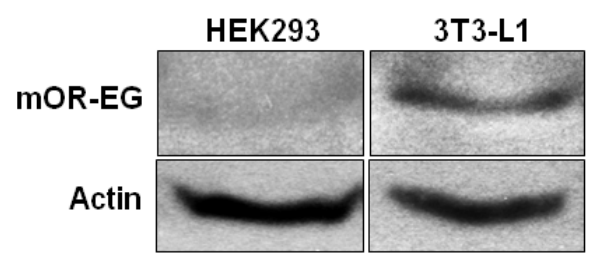

Figure 1. Expression of eugenol receptor (mOR-EG) in 3T3-L1 and HEK293 cells 


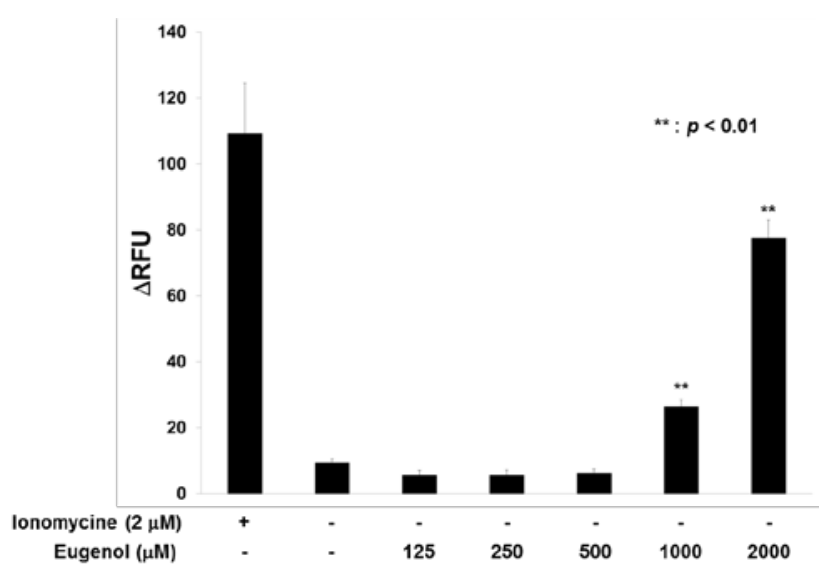

Figure 2A. Changes in $\mathrm{Ca}^{2+}$ level induced by eugenol in 3T3-L1 cells. Ionomycin $(2 \mu \mathrm{M})$ was used as a positive control, and DMSO (1\%) was used as a negative control. Data represent the mean $\pm \mathrm{SD}(\mathrm{n}=3)$. **: $p<0.01$. $\triangle \mathrm{RFU}$, change in relative fluorescence unit

In addition, eugenol (2 $\mathrm{mM})$ significantly increased cAMP levels by 2-fold after 7 min treatment in 3T3-L1 cells compared to controls (Figure 2B). CREB phosphorylation, a downstream target of cAMP, was also increased by eugenol in dose-dependent manner (Figure 2C). Higher concentrations (4 and $8 \mathrm{mM}$ ) and longer incubation times with eugenol induced cell death of 3T3L1 cells, consistent with our previous report [17]. These data demonstrate that mol fr 73 is expressed in 3T3-L1 cells and is activated by its agonist, eugenol, resulting in increased cAMP, $\mathrm{Ca}^{2+}$, and CREB phosphorylation. Thus, the odorant-induced signal pathway is activated through CAMP, CREB, and $\mathrm{Ca}^{2+}$ via an odorant in nonchemosensory cells, and this system may useful for the investigating the different physiological roles of ORs in non-olfactory tissues and cells.

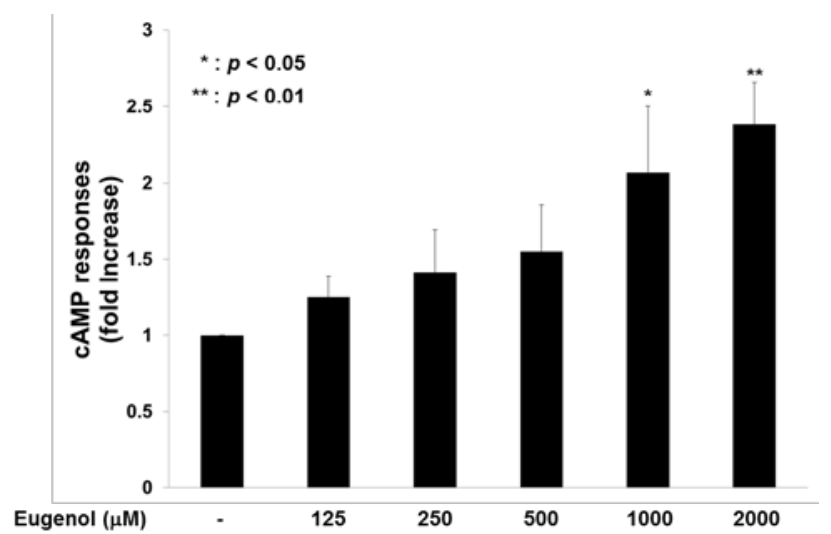

Figure 2B. Eugenol increases cAMP levels in 3T3-L1 cells. Eugenol (125 to $2000 \mu \mathrm{M}$ ) was administered for 7 min after starvation in serumfree DMEM (high glucose) for 16-18 h. The final concentration of DMSO in all samples was $1 \%$. Data represent the mean $\pm S D(n=3)$

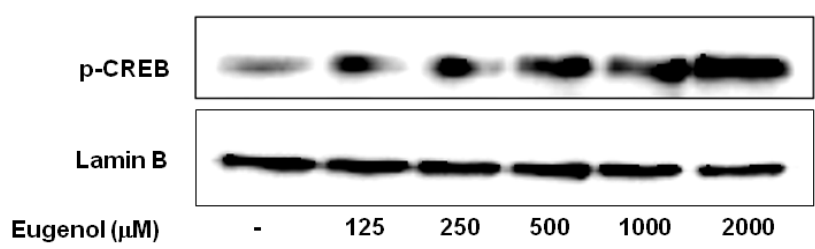

Figure 2C. Western blot analysis of total and phosphorylated CREB after treatment with eugenol for $7 \mathrm{~min}$. Forty-five micrograms of protein was separated by SDS-PAGE. The final concentration of DMSO in all samples was $1 \%$

\subsection{POR Decreased Eugenol-induced $\mathrm{Ca}^{2+}$ and CAMP in 3T3L1 Cells}

Next, we investigated the effects of POR on eugenolinduced signal transduction pathway in 3T3-L1 cells. As shown in Figure 3A, the eugenol-mediated increase in $\mathrm{Ca}^{2+}$ was significantly decreased by 30 min pretreatment with different concentrations of POR. Compared to the positive control, $\mathrm{Ca}^{2+}$ was decreased by $25 \%, 20 \%$, and $90 \%$ following pretreatment with 200, 400, and 800 $\mu \mathrm{g} / \mathrm{mL}$ POR, respectively.

In addition, compared to the positive control, cAMP levels were decreased up to $50 \%$ and $75 \%$ by $30 \mathrm{~min}$ pretreatment with 400 and $800 \mu \mathrm{g} / \mathrm{mL}$ POR, respectively (Figure 3B). To ensure that these results were not biased by the toxic effect of POR in 3T3-L1 cells, cell viability was determined after pre-treatment with different concentrations of POR. As shown in Figure 3C, no toxic effect was observed at up to $800 \mu \mathrm{g} / \mathrm{mL}$ POR. However, many cells were dead and their morphology was abnormal when the cells were treated with 1.6 and $3.2 \mathrm{mg} / \mathrm{mL}$ POR. Thus, all experiments were carried out with lower than 0.8 $\mathrm{mg} / \mathrm{mL}$ POR to remove any toxic effects of POR. These data strongly suggest that POR inhibits odorant-induced signal transduction by regulating $\mathrm{Ca}^{2+}$ and cAMP in 3T3L1 cells without any toxic effect.

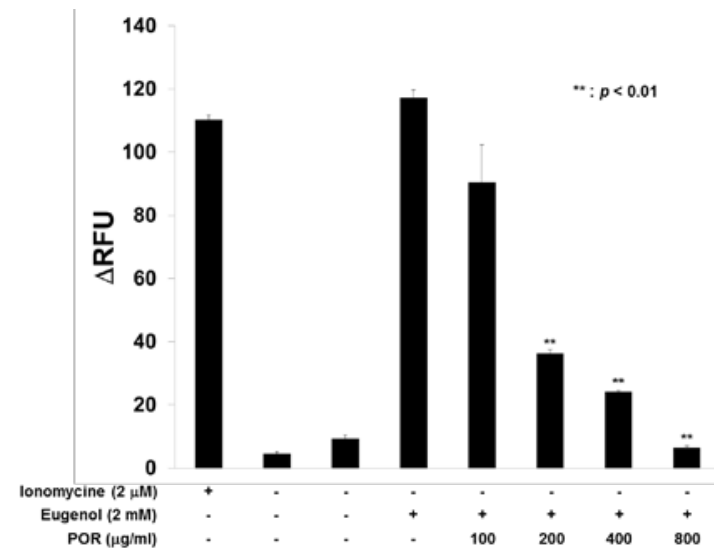

Figure 3A. Changes in eugenol-induced $\mathrm{Ca}^{2+}$ levels in 3T3-L1 cell safter pretreatment with POR for $30 \mathrm{~min}$. Ionomycin $(2 \mu \mathrm{M})$ was used as appositive control, and DMSO (1\%) was used as negative control. Data represent the mean $\pm \mathrm{SD}(\mathrm{n}=3)$. **: $p<0.01 . \Delta \mathrm{RFU}$, change in relative fluorescence unit

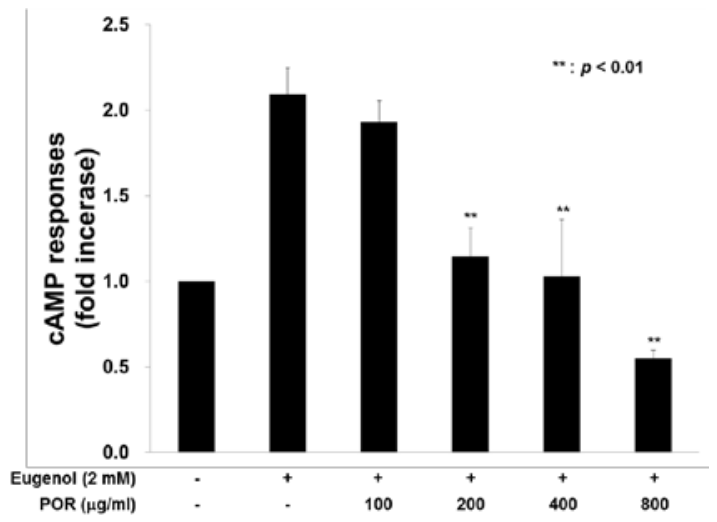

Figure 3B. Change sineugenol-induced cAMP level sin 3T3-L1 cell safter pretreatment with POR for $30 \mathrm{~min}$. The final concentration of DMSO in all samples was $1 \%$. Data represent the mean \pm SD $(n=3)$. $\triangle \mathrm{RFU}$, change in relative fluorescence unit 


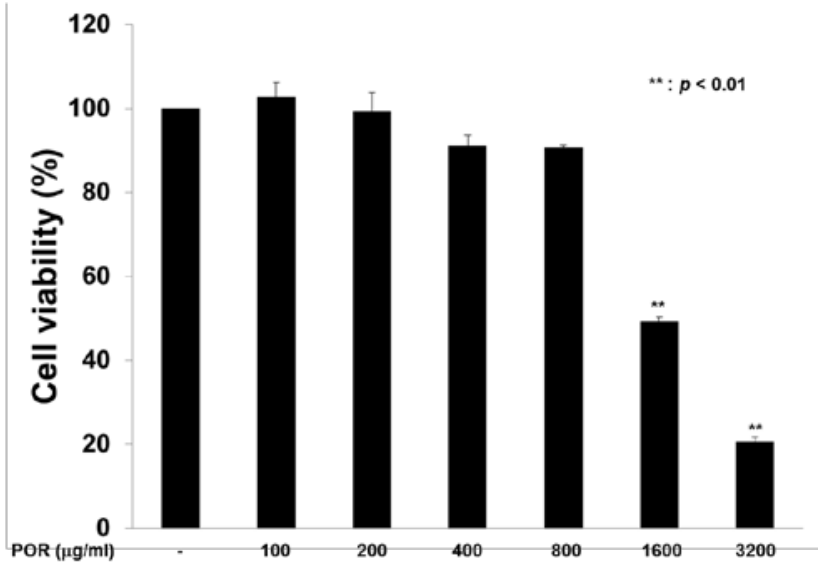

Figure 3C. WST-1 assays of cell viability. Cell survival was evaluated after treatment of 3T3-L1 cells with 100, 200, 400, 800, 1600, 3200 $\mu \mathrm{g} / \mathrm{mL}$ POR for $30 \mathrm{~min}$. Data represent the mean $\pm \mathrm{SD}(\mathrm{n}=3)$

\subsection{POR Suppressed Rap1A and CREB Phosphorylation in 3T3L1 Cells}

Next, we investigated how POR affects molecules involved inodorant-induced signal transduction. Since phosphorylation CREB is important for OST signaling pathway [19] and Rap1a can be activated by cAMP, we assessed the phosphorylation state of these proteins. As shown in Figure 4, we found for the first time that a 30 min pre-treatment with $800 \mu \mathrm{g} / \mathrm{mL}$ POR significantly decreased the phosphorylation of Rap1A in OST pathway, whereas treatment with POR concentrations below 400 $\mu \mathrm{g} / \mathrm{mL}$ did not have any effect. It suggests that in nonchemosensory cells, OST pathway shares the same regulating mechanism where cAMP and its downstream targets such as CREB and Rap1A play as second messengers. Similarly, CREB phosphorylation was decreased by $800 \mu \mathrm{g} / \mathrm{mL}$ POR, but 200 and $400 \mu \mathrm{g} / \mathrm{mL}$ POR had no effect. These results could be explained by the fact that changes in cAMP and $\mathrm{Ca}^{2+}$ occurvery early in the process, but phosphorylation events occur later in OST pathway, so 30 min might not be enough time to observe changes at lower POR concentrations.

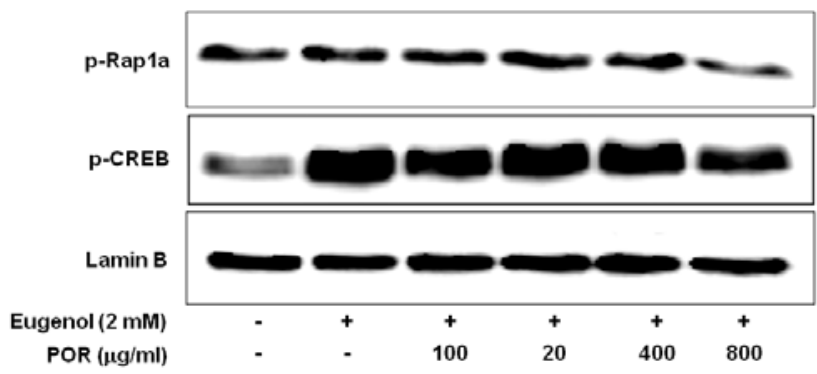

Figure 4. Western blot analysis of total and phosphorylated Rap1a and CREB after pretreatment with POR for 30 min. Forty-five micrograms of protein was separated by SDS-PAGE. The final concentration of DMSO in all samples was $1 \%$

In summary, this study demonstrates that POR modulates $\mathrm{Ca}^{2+}$ and cAMP levels, as well as the phosphorylation of Rap1A and CREB induced by an odorant in non-chemosensory 3T3-L1 cells. This finding expands our understanding of the olfactory signaling pathway and developed a model system to investigate the physiological roles of OR in non-olfactory tissue.

\section{Acknowledgements}

This study was supported by a grant from the Korea Food Research Institute (E0143043495). The authors declare that they have no conflicts of interest.

\section{Reference}

[1] Gu, M., Zhang, Y.,Fan, S., Ding, X.,Ji,G., Huang, C., "Extracts of Rhizoma Polygonati Odorati prevent high-fat diet-induced metabolic disorders in C57BL/6 mice”, PLoS One, 8 (11), e81724, 2013.

[2] Park, U.H., Jeong, J.C., Jang, J.S., Sung, M.R., Youn, H., Lee, S.J., Kim, E.J., Um, S.J., "Negative regulation of adipogenesis by kaempferol, a component of Rhizoma Polygonati Falcatum in 3T3-L1 cells”, Biological and Pharmaceutical Bulletin, 35 (9), 1525-1533, 2012.

[3] Xian, Y.F., Lin, Z.X., Xu, X.Y.,Su, Z.R., Chen, J.N., Lai, X.P., Ip, S.P., "Effect of Rhizoma Polygonati on 12-Otetradecanoylphorbol-acetate-induced ear edema in mice”, Journal of Ethnopharmacology, 142 (3),851-8566, 2012.

[4] Chen, H., Feng, R., Guo, Y., Sun, L., Jiang, J., “Hypoglycemic effects of aqueous extract of Rhizoma Polygonati Odorati in mice and rats”, Journal of Ethnopharmacology, 74 (3), 225-229, 2001.

[5] Kang, N., Koo, J., "Olfactory receptors in non-chemosensory tissues”, BMB Reports, 45 (11), 612-622, 2012.

[6] Griffin, C.A., Kafadar, K.A., Pavlath, G.K., "MOR23 promotes muscle regeneration and regulates cell adhesion and migration", Develpmental Cell, 17 (5), 649-661, 2009.

[7] Fukuda, N., Yomogida, K., Okabe, M., Touhara, K., "Functional characterization of a mouse testicular olfactory receptor and its role in chemonsensing and regulation of sperm motility”, Journal of Cell Science, 117 (Pt24), 5835-5845, 2004.

[8] Pluznick, J.L., Zou, D.J., Zhang, X., Yan, Q., Rodriguesz-Gil, D.J., Eisner, C., Wells, E., Greer, C.A., Wang, T., Firestein, S., Schnermann, J., Caplan, M.J., "Functional expression of the olfactory signaling system in the kidney", Proceedings of the National Academy of Sciences of the United States of America, 106 (6), 2059-2064, 2009.

[9] Dooley, R., Mashukova, A., Toetter, B., Hatt, H., Neuhaus, E.M., "Purinergic receptor antagonists inhibit odorant-mediated CREB phosphorylation in sustentacular cells of mouse olfactory epithelium”, BMC Neuroscience, 12 (86), 1471-2202-12-86, 2011.

[10] Sheikh, I.A., Koley, H., Chakrabarti, M. K., Hoque, K.M., “The Epac1 signaling pathway regulates $\mathrm{Cl}^{-}$secretion via modulation of apical KCNN4c channels in Diarrhea”, The Journal of Biological Chemistry, 288 (28), 20404-20415, 2013.

[11] Motawea, H.B.B., Jeyaraj, S.C., Eid, A.H., Mitra,S., Unger, N.T., Ahmed, A.A.E., Flavahan, N.A., Chotani, M.A., "Cyclic AMPRap1A signaling mediates cell surface translocation of microvascular smooth muscle $\square$ 2c-adrenoreceptors through the actin-binding protein filamin-2”, American Journal of Physiology Cell Physiology, 305, C829-C845, 2013.

[12] Buck, L.B., Axel, R., "A novel multigene family may encode odorant receptors: a molecular basis for odor recognition”, Cell, 65, 175-187, 1991.

[13] Wang, Z., Subramanya, A.R., Satlin, L.M., Pastor-Soler, N.M., Carattino, M.D., Kleyman, T.R., "Regulation of largedonductance $\mathrm{Ca}^{2+}$-activated $\mathrm{K}^{+}$channels by WNK4 kinase", American Journal of Physiology Cell Physiology, 305, C846-C853, 2013.

[14] Lowe, G., Nakamura, T., Gold, G.H., “Adenylatecyclase mediates olfactory transduction for a wide variety of odorants", Proceedings of the National Academy of Sciences of the United States of America, 86, 5641-5645, 1989.

[15] Nakamura, T., Gold, G.H., "A cyclic nucleotide-gated conductance in olfactory receptor cilia”, Nature, 325, 442-444, 1987.

[16] Jeyaraj, S.C., Unger, N.T., Eid, A.H., Mitra, S., El-Dahdah, N.P., Quilliam, L.A., Flavahan, N.A., Chotani, M.A., "Cyclic AMPRap1A signaling activates RhoA to induce $\square$ 2c-adrenoceptor translocation ot the cell surface of microvascular smooth muscle cells", American Journal of Physiology Cell Physiology, 303, C499-C511, 2012. 
[17] Yoon, Y.C., Hwang, J.T., Sung, M.J., Wang, S., Munkhtugs, D. Rhyu, M.R., Park, J.H., "Inhibitory effect of luteolin on the odorant-induced cAMP level in HEK 293 cells expressing the olfactory receptor”, Biofactors, 38 (5), 360-364, 2012.

[18] Choi, Y., Hur, C.G., Park, T., "Induction of olfaction and cancerrelated genes in mice fed a high-fat diet as assessed through the mode-of-action by network identification analysis”, Plos One, 8 (3), e56610, 2013.

[19] Grewal, S.S., Fass, D.M., Yao, H., Ellig, C.L., Goodman, R.H. Stork, P.J., "Calcium and cAMP signals differentially regulate cAMP-responsive element-binding protein function via a Rap1extracelluar signal-regulated kinase pathway", The Journal of Biological Chemistry, 275 (44), 34433-34441, 2000. 